\title{
Effects of three cognitive strategies on long-distance running
}

\author{
DAVID E..SAINTSING, CHARLES L. RICHMAN, and DONALD B. BERGEY \\ Wake Forest University, Winston-Salem, North Carolina
}

\begin{abstract}
The present research was designed to assess the effects of three cognitive strategies on longdistance running. In comparison with the control subjects, the subjects who were administered associative, task-specific instructions demonstrated a substantial improvement in their running times. Dissociative and psyching-up instructions were no more effective in improving running times than were control instructions. A positive relationship was found between the use of associative and dissociative instructions and running times.
\end{abstract}

Although little research has been conducted in the use of cognitive coping strategies to enhance motor performance, the effect of these strategies in sports has recently been acknowledged. Many athletes and coaches in a variety of sports refer to the importance of mental preparation in maximizing athletic performance. For example, Jack Nicklaus's use of mental imagery in golf led him to write a book on mental preparation.

Numerous cognitive strategies have been used to improve an athlete's ability to compete. We focus on three of these strategies. The first of these is psyching-up. It is commonly accepted that most people perform best when motivated. Several investigators have used psyching-up to enhance motor performance. Shelton and Mahoney (1978) conducted one of the first studies designed to assess the effects of this strategy. Olympic-style weight lifters were tested on gripping strength and were instructed to use any psyching-up strategy that suited them. The control group was instructed to count backward between trials. The findings clearly indicated that the experimental subjects' gripping behavior was facilitated by their use of psyching-up strategies, whereas the control subjects actually showed a decrement in behavior. When questioned about style of psyching-up, the weight lifters' responses included statements of (1) self-efficacy and personal ability, (2) attentional glories, (3) preparatory arousal, and (4) imagery. A majority used a combination of the four psyching-up strategies.

Weinberg, Gould, and Jackson (1980) used open-ended psyching-up instructions on three different motor tasks, resulting in a facilitation on isokinetic leg strength tasks. The instructions failed, however, to affect stabilometer balance and speed of arm movement exercises. In a within-subjects design, Caudill and Weinberg (1983) ob-

This article is based in part on an honors thesis submitted by the first author to the Department of Psychology, Wake Forest University, in partial fulfillment of the requirements for honors. This research was supported in part by the Wake Forest University Research and Publication Fund. Requests for reprints should be sent to Charles L. Richman, Department of Psychology, P.O. Box 7778, Wake Forest University, Winston-Salem, NC 27109. served the effects of psyching-up instructions on $100-\mathrm{m}$ dash sprinters and 60 -m hurdlers. They found significant improvements in athletes given psyching-up instructions relative to control athletes. It is interesting to note that all these studies cited used short 1- to 2-day training-testing intervals. Little field research has been done with athletes over extended periods of time.

Another cognitive strategy that has been used in sports is termed association. Rushall (1984) described this strategy as containing "developed, task-specific content" (p. 53). Crossman and Rushall (1977) used the associative strategy in a laboratory setting with skilled and trained athletes performing a treadmill running task to exhaustion. They found that several of these subjects experienced significant gains in performance. The researchers also pointed out that "developing deliberate strategies, whether or not they were task specific, enhanced performance by an average of $10 \%$ over unaided or nonformulated conditions" (p. 53).

Chorkawy (1982) and Ford (1983) performed a series of controlled studies that involved numerous strategies, including association. Their subjects were nationally ranked age-group swimmers. Improvements up to $15 \%$ above their previous maximum performance were noted in 4 of 6 swimmers when task-specific thought was used.

Finally, dissociation is a cognitive strategy that has been used to prevent the mind from focusing on internal cues (i.e., perceived fatigue and pain). Rushall (1984) termed this "developed non-task-specific thought." The subject is encouraged to concentrate on some theme (or place) external to the task. Another form of dissociation is to have a more specific and developed method of preventing the processing of internal cues. Morgan, Horstman, Cymerman, and Stokes (1983) used the "keyword" concept for runners. The subjects repeated the word "down" on every stride. In a controlled laboratory experiment with U.S. Army soldiers as subjects, Morgan et al. found a significant improvement in running by their dissociation subjects.

Pennebaker and Lightner (1980) showed that external cues (i.e., terrain) compete with internal cues (i.e., ven- 
tilation, muscle pain) naturally. Subjects in this study ran both on a track and a cross-country course. It was found that their times were faster on the cross-country course, yet perceived exertion was the same. Pennebaker and Lightner concluded, "Given that subjects were focusing on external cues to a higher degree on a cross-country course, their processing of internal sensations was restricted"' (p. 171).

The present study focused on the effects on running speed of the three previously mentioned cognitive coping strategies: psyching-up, association, and dissociation. These cognitive strategies were tested with novice runners in three experimental groups and a control group. Our hypothesis was that the association, dissociation, and psyched-up subjects would perform significantly better than the control subjects.

\section{METHOD}

\section{Subjects}

The subjects were 31 male and 19 female undergraduate students from a physical conditioning class at Wake Forest University; participation was voluntary. There were two sections of the course, taught by the same instructor.

\section{Apparatus}

The subjects were trained on the cross-country courses at the university. They were tested on a 1.5 -mile run on a standard 400 -m outdoor asphalt-base track. The subjects in each of the four groups were administered instructions in a large room. A questionnaire was given to each subject on the final test run to estimate the percentage of time the instructions were used.

\section{Procedure}

The first 2 weeks of class emphasized proper techniques of running and allowed for a training period before testing. The subjects were then tested on the 1.5-mile run. During the experiment, four measures were taken approximately 2 weeks apart. The subjects were rank ordered from fastest to slowest based on the mean speed of Run 1 and Run 2 . If a subject missed Run 1 or 2 , the run available was used in the ranking. If both runs were missed, the subject was dropped from the experiment. The subjects were then assigned to one of the four groups so that they were matched according to their initial running times. A week after Run 2, the subjects were told that they were going to be in an experiment that dealt with the relationship between the mental and physical self. The subjects were then taken one group at a time into a large room and given instructions as follows:

Association group-The subjects were told to take the time prior to each run to concentrate on the technique of running (i.e., the arm drive, the stride, the breathing, foot placement). They were instructed to keep their thoughts specific to the task of running. They were told to continue with this thought process during all training and testing runs, and to continue this until the experiment ended in order to enhance their performance.

Table 1

Mean Running Time Difference Scores for Groups Association, Dissociation, Psyching-Up, and Control

\begin{tabular}{cc}
\hline & Running Time Difference \\
\cline { 2 - 2 } Group & Scores \\
\hline Association & 58.3 \\
Dissociation & 39.5 \\
Psyching-up & 37.9 \\
Control & 26.8 \\
\hline
\end{tabular}

Note-Scores are given in seconds.
Table 2

Spearman Rho Correlations Performed on the Experimental Groups' Pre- Minus Post-Running Time Difference Scores and Subjects' Estimates of the Time They Used Their Respective Strategies, and the Average Percentages of Time the Subjects Used Their Strategies

\begin{tabular}{lcrrcc}
\hline \multicolumn{1}{c}{ Group } & Spearman Rho & $d f$ & $t$ Test & $p$ & $\%$ Time \\
\hline Association & +.56 & 10 & 2.14 & $<.05$ & $62 \%$ \\
Dissociation & +.70 & 8 & 2.77 & $<.01$ & $43 \%$ \\
Psyching-up & +.26 & 10 & .85 & $>.10$ & $56 \%$ \\
\hline
\end{tabular}

Dissociation group-The subjects were told that they would be concentrating on what are called non-task-specific thoughts. These thoughts would be of something other than the task of running. They were instructed to say the word "down" on every stride of training as well as testing runs and to concentrate on using this procedure throughout the semester to aid in enhancing their performance.

Psyching-up group-The subjects were told to use their emotions in any way they wanted to charge themselves up for all runs. They were to do anything they needed to do to become fired up emotionally to aid their performance.

Control group-The subjects were given a 2-min lecture on the physiological benefits of running.

All subjects were asked not to speak to anyone about their particular instructions until after the semester had ended. The subjects were told that the rationale behind this was that they could jeopardize the validity of the results if they conferred with one another about their instructions.

The subjects were given $5 \mathrm{~min}$ prior to each run to prepare themselves for the use of their respective strategies. The subjects were periodically reminded during the semester by their instructor to think about their specific instructions. This served to "boost" the use of instructions during the semester as well as to minimize outside interference by the experimenter.

Two measures were taken after the subjects received instructions, the first 1 week following their instructions, and the other 3 weeks following their instructions. After the final run, the subjects received the previously mentioned manipulation check to determine if or to what extent they used their strategies. The subjects were then briefed on the purpose, procedures, and hypothesis of the experiment.

\section{RESULTS}

A simple analysis of variance was performed on the running time difference scores (pre- minus post-strategy training) for the four training groups (Groups Association, Dissociation, Psyching-up, and Control). This analysis revealed a statistically significant effect $[F(3,49)=3.32$, $p<.05$ ]. Pair-wise multicomparison tests showed, as indic ated in Table 1, that Group Association subjects' running times improved to a greater extent than those of subjects trained in Group Dissociation $(p<.05)$, Group Psyching-up $(p<.05)$, and Group Control $(p<.01)$. No other pair-wise comparison was found to be statistically significant $(p s>.10)$.

Spearman rho correlational analyses were performed on the pre- minus post-strategy training running scores and the subjects' estimate of the percentage of time they used their respective strategies prior to and during their test runs. Table 2 shows that Group Association and Group Dissociation subjects' running improvement scores were positively related to the use of their respective strategies, whereas Group Psyching-up subjects failed to demonstrate this relationship. Table 2 also presents the 
average percentages of time that the subjects estimated they used their respective strategies.

\section{DISCUSSION}

The present research suggests that long-distance running speeds may be facilitated by association training, whereas, dissociative or psyching-up training has little effect on performance. The former result supports the finding in Crossman and Rushall's (1977) treadmill study that associative training delays long distance runners' reports of exhaustion. The present findings, however, fail to support those of Morgan et al. (1983), who demonstrated that running speeds were facilitated following dissociative training, and those of Caudill and Weinberg (1983), who found similar positive effects by using psyching-up procedures. It is puzzling why we did not find similar effects in our dissociative and psyching-up groups. It is conceivable, although speculative, that psyching-up facilitates anaerobic performance (i.e., requirements of short bursts of energy), whereas aerobic behavior is aided by associative strategies. This hypothesis gains support from Caudill and Weinberg (1983), who showed that psyching-up facilitated running speeds in the $100-\mathrm{m}$ dash and $60-\mathrm{m}$ hurdles, and Shelton and Mahoney (1978), who reported that psyching-up improved the performance of weight lifters. Morgan et al.'s (1983) finding of facilitation of running following dissociative training may have been due, in part, to their procedure of training followed immediately by testing of their subjects; that is, it is plausible to assume that the simplistic training procedure of requiring subjects to focus on simple external stimuli may only be beneficial when the training-testing intervals are relatively short. Whether these post hoc assumptions are correct is currently being investigated by varying the training task (e.g., anaerobic vs. aerobic), the nature of the instructions (e.g., associative, dissociative, and psyching-up), and the time between training and testing.

The present results also showed a relationship between the use of associative and dissociative strategies and running times, suggesting that when the subjects employed these strategies their performance was improved. It is also plausible that these factors were related to a third, untested, factor (e.g., the subject's desire to please the experimenter); that is, the subject may have said what he/she thought the experimenter wanted to hear (e.g., "I used your procedures") and may have tried to please the experimenter by showing large performance gains. This hypothesis, however, loses credibility when one considers the psychingup subjects, for whom use of strategy and running time improvements were not related.

\section{REFERENCES}

Caudill, D., \& Weinberg, J. (1983). Psyching-up track athletes: A preliminary investigation. Journal of Sport Psychology, 5, 231-235.

CHORKAWY, A. L. (1982). The effects of cognitive strategies on the performance of female swimmers. Unpublished master's thesis, Lake Head University, Thunder Bay, Ontario.

Crossman, J. E., \& Rushall, B. S. (1977, April). The effects of cognitive strategies on the performance of athletes. Paper presented at the AAHPERD National Convention, Seattle, Washington.

FORD, D. (1983). The effects of cognitive strategies on swimming performance. Unpublished master's thesis, Lake Head University, Thunder Bay, Ontario.

Morgan, W. P., Horstman, D. H., Cymerman, A., \& Stokes, J. (1983). Facilitation of physical performance by means of a cognitive strategy. Cognitive Therapy \& Research, 7, 251-264.

Pennebaker, J. A., \& Lightner, J. M. (1980). Competition of internal and external information in an exercise setting. Journal of Personality \& Social Psychology, 39, 165-174.

Rushall, B. S. (1984). Content of competitive thinking. In W. F. Straub \& J. M. Williams (Eds.), Cognitive sport psychology (pp. 51-62). Lansing, NY: Sport Science Associates.

Shelton, A. O., \& MAHONEY, M. J. (1978). The content of effect of "psyching-up" strategies in weight lifters. Cognitive Therapy \& Research, 2, 275-284.

WeinberG, R. S., Gould, D., \& JACKSON, A. (1980). Cognitive and motor performance: Effect of psyching-up on three motor tasks. Cognitive Therapy \& Research, 4, 239-245.

(Manuscript received for publication June 1, 1987.) 